\title{
Effect of different technologies and animal manures on solid-liquid separation efficiencies
}

\author{
Giorgia Cocolo, ${ }^{1}$ Silvia Curnis, ${ }^{1}$ Maibritt Hjorth, ${ }^{2}$ Giorgio Provolo ${ }^{1}$ \\ ${ }^{1}$ Department of Agricultural Engineering, University of Milano, Italy; ${ }^{2}$ Department of Engineering, \\ University of Aarhus, Tjele, Denmark
}

\begin{abstract}
Solid-liquid separation is a widely used manure treatment option. However, little information is available to predict separator performance in a specific operating condition. This study investigates the effect on the separation efficiency of animal species (cattle and swine), use of flocculants, and separator construction and operating characteristics (filtration, pressurised filtration, settling and centrifugation). Using data available from published experiments, we evaluated correlations of the separation efficiencies with the physical and chemical characteristics of the inlet slurries (dry matter, total nitrogen, ammoniacal nitrogen, phosphorus and potassium). Dry matter concentration of the input manure was found to be the best parameter used to calculate and validate regression equations. Regressions for the operating conditions of 7 of the 14 subgroups evaluated were significant $(\mathrm{P}<0.05)$ for at least one parameter. Pressurised filtration seems to be the process best represented by these regressions that can predict dry matter and nitrogen efficiency with relative root mean squared errors of less than $50 \%$. However, they could only be used for some of the parameters and separation techniques. Therefore, it was not possible to use the available experimental data to define and validate empirical predictive models for all the conditions. Specific studies are needed to define more precise and physically-based models.
\end{abstract}

Correspondence: Giorgia Cocolo, Department of Agricultural Engineering, University of Milano, via Celoria 2, 20133 Milano, Italy.

E-mail: giorgia.cocolo@unimi.it

Key words: correlation, efficiency, manure, separation, treatment.

Acknowledgements: supported by Progetto AGER, grant n. 2010-2220.

Received for publication: 3 May 2012.

Accepted for publication: 3 August 2012.

(C) Copyright G. Cocolo et al., 2012

Licensee PAGEPress, Italy

Journal of Agricultural Engineering 2012; XLIII:e9

doi:10.4081/jae.2012.e9

This article is distributed under the terms of the Creative Commons Attribution Noncommercial License (by-nc 3.0) which permits any noncommercial use, distribution, and reproduction in any medium, provided the original author(s) and source are credited.

\section{Introduction}

Globally, intensification of agricultural systems increases the environmental impact of food production, leading to large amounts of manure that are used in crop systems in excess of crop requirements (Petersen et al., 2007). These excesses may result in discharge and emission of pollutants, such as nitrogen $(\mathrm{N})$ and phosphorus $(\mathrm{P})$ compounds, to the environment.

In order to face these environmental problems, many farmers need to find technologically and economically effective solutions (Balsari et al., 2006). Nowadays, there is a wide range of manure treatment processes that meet various requirements (Burton and Turner, 2003). Among these techniques, solid-liquid separation is one of the cheapest treatment options and is often feasible within the specific farming system (Burton, 2007). Solid-liquid treatment allows farmers to separate solids from slurry, producing two final products; a dry matter (DM)-rich and nutrient-rich fraction, and a liquid fraction that can both be managed separately. In particular, the nutrient- and DM-rich fraction could be more easily transported off farm or to fields far from the farmstead, reducing transportation costs (Møller et al., 2000; Bertora et al., 2008). Furthermore, solid-liquid separation can be followed by other manure treatments, such as anaerobic digestion, composting or $\mathrm{N}$ reduction (Zhang and Lei, 1998; Tilche et al., 1999; Møller et al., 2007; Brito et al., 2008). Two solid-liquid separation technologies could also be coupled in order to increase the efficiency of the treatment process, as demonstrated by previous studies (Westerman and Bicudo, 2000; Chastain et al., 2001b; Converse and Karthikeyan, 2004; Balsari et al., 2006; Fangueiro et al., 2008a, 2008b and 2008c). Several separation devices have been designed to carry out the solid-liquid separation treatment by different processes. Hence, separation techniques can be classified according to their operation (Table 1) (Zhang and Westerman, 1997; Ford and Flemming, 2002; Hjorth et al., 2010). To more efficiently remove nutrients, which are in smaller particles, physical and mechanical separation can be performed with the addition of chemical additives, flocculants and/or coagulants (Vanotti et al., 2002). Several additive types have been studied in various experiments to coagulate manure, to flocculate it or to remove ortophosphorate $\left(\mathrm{PO}_{4}{ }^{3-}\right)$. These are iron ( $\left.\mathrm{Fe}\right)$, aluminium ( $\left.\mathrm{Al}\right)$ and calcium (Ca) salts, several types of polyacrylamides (PAM), and clay (Henriksen et al., 1998; Vanotti and Hunt, 1999; Vanotti et al., 2002; Westerman and Arogo Ogejo, 2005; Møller et al., 2007; Rico et al., 2007; Garcia et al., 2009; Hjorth et al., 2009). The performance of the different separation techniques mentioned above is often expressed by the separation efficiency. This could be expressed thorough the removal efficiency or the separation index (Burton, 2007; Hjorth et al., 2010). The removal efficiency $(\mathrm{R})$ expresses efficiency in removing a specific compound (DM or nutrients) from slurry to the solid fraction:

$R(\%)=1-\frac{c(x) \text { liquid }}{c(x) \text { slurry }} \cdot 100$ 
where $c(x)$ slurry and $c(x)$ liquid are the concentrations of DM or nutrients $(\mathrm{N}, \mathrm{P})$ in the slurry and the liquid fraction.

The separation index (Et) is the ratio of the total mass recovery of a given component (DM or nutrients) in the solid phase as a proportion of the total input of that component (DM or nutrient) (Svarovsky, 1981; Møller et al., 2000; Burton 2007). This index expresses the distribution of a specific compound in the solid and the liquid fraction:

$E t=\frac{m(x) \text { solid }}{m(x) \text { slurry }} \cdot 100$

where $m(x)$ slurry and $m(x)$ solid are the mass of DM or nutrients (N, $P)$ in the slurry and the solid fractions.

The separation efficiency is influenced by several factors (Burton and Turner, 2003):

- Type of separator;

- Sieve mesh size or centrifugal force;

- Manure type (species, pre-treatments and total solids' content);

Use of additives.

Therefore, as described by Zhang and Westerman (1997), the abovementioned separator types have different separation efficiencies, leading to the production of end products with different characteristics that make them preferable for certain uses. Thus, because the performance of the various separator types differs, a decision support tool is necessary to identify the separation technology most suitable for the farmer's needs, given particular manure properties.

In recent years, several decision support systems for manure management have been developed (Karmakar et al., 2007), but only some of them take manure treatment processes into consideration. Additionally, few models have been elaborated for solid-liquid separa- tion processes. For instance, Rico et al. (2006) obtained a predictive empirical model to estimate the concentrations of DM, volatile solids (VS), carbon oxygen demand (COD) and total organic carbon in the solid fraction, as functions of the doses of ferric chloride $\left(\mathrm{FeCl}_{3}\right)$ and a medium cationic polyacrylamide (MCP1). In other studies, Chastain and Vanotti (2003) defined some correlation equations to predict the separation efficiencies for DM, VS, COD, N and P for gravity settling of swine manure. However, the proposed models for solid-liquid separation concern only one separation process (i.e. chemical separation or gravity settling). For this reason, they could not be used as tools to support our decisions because they do not estimate and compare the separation efficiencies of different devices and then identify the better solution according to the farmer's needs.

Table 1. Separator types grouped according to their separation technique.

\begin{tabular}{ll} 
Separation technique & Separator type \\
Gravity filtration & Inclined screen \\
& Vibrating screen \\
& Rotating screen \\
Pressurised filtration & Screw press \\
& Roller press \\
& Belt press \\
\hline Centrifugation & Decanting centrifuge \\
& Settling \\
& Sedimentation \\
\hline
\end{tabular}

Table 2. Values count for separation efficiencies and references for collected data. Data are divided according to separator type.

\begin{tabular}{|c|c|c|c|c|c|}
\hline Separator type & & cien & $y(\%)$ & & Source \\
\hline & DM & $\mathbf{N}$ & $\mathrm{NH}_{4}$ & P & \\
\hline Belt press & 10 & 11 & & 12 & $\begin{array}{l}\text { Campos et al., 2002; Henriksen et al., 1998; Hjorth et al., 2009; Møller et al., 2000; Pieters et al., 1999; } \\
\text { Walker and Kelley, 2005; Zhang and Westerman, 1997. }\end{array}$ \\
\hline Centrifuge & 69 & 68 & 19 & 68 & $\begin{array}{l}\text { Balsari et al., 2006; Duarte et al., 2001; Fangueiro et al., 2009; Hansen et al., 2006; Karakashev et al., } \\
\text { 2008; Loyon et al., 2006; Melse and Verdoes, 2005; Møller et al., 2002; Møller et al., 2007; Petersen and } \\
\text { Sørensen, 2008; Pieters et al., 1999; Sørensen and Møller, 2006; Westerman and Arogo Ogejo, 2005; } \\
\text { Zhang and Westerman, 1997. }\end{array}$ \\
\hline Inclined screen & 67 & 66 & 7 & 60 & $\begin{array}{l}\text { Barrow et al., 1997; Chastain et al., 2001a; Chastain, 2009; Garcia et al., 2007a; Garcia et al., } \\
\text { 2009; Gonzàlez-Fernàndez et al., 2008; Hill and Baier, 2000; Kaparaju and Rintala, 2008; Kunz et al., 2009; } \\
\text { Meyer } \text { et al., 2007; Møller et al., 2000; Rico et al., 2007; Vanotti et al., 2002; Wright, 2005; Zhang and Lei, } \\
\text { 1998; Zhang and Westerman, 1997. }\end{array}$ \\
\hline Roller press & 14 & 14 & 1 & 14 & Balsari et al., 2006; Curnis, 2008. \\
\hline Rotating screen & 2 & 2 & & 12 & $\begin{array}{l}\text { Garcia et al., 2007b; Gooch et al., 2005; Marcato et al., 2008; Møller et al., 2000; Walker and Kelley, 2005; } \\
\text { Zhang and Westerman, } 1997 .\end{array}$ \\
\hline Screw press & 44 & 28 & 4 & 29 & $\begin{array}{l}\text { Balsari et al., 2006; Bertora et al., 2008; Brito et al., 2008; Burns et al., 2003; Burton and Turner, 2003; } \\
\text { Chastain et al., 2001b; Converse et al., 2000; Converse and Karthikeyan, 2004; Curnis, 2008; } \\
\text { Dinuccio et al., 2008; Fangueiro et al., 2008a, 2008b and 2008c; Loyon et al., 2006; Melse and Verdoes, } \\
\text { 2005; Møller et al., 2002; Møller et al., 2000; Pieters et al., 1999; Westerman and Bicudo, 2000; Westerman } \\
\text { and Arogo Ogejo, 2005; Wu, 2007. }\end{array}$ \\
\hline Sedimentation & 69 & 86 & 19 & 86 & $\begin{array}{l}\text { Barrow et al., 1997; Campos et al., 2008; Chastain et al., 2001a; Converse and Karthikeyan, 2004; } \\
\text { Fangueiro et al., 2008a, 2008b and 2008c; Garcia et al., 2007b; Gooch et al., 2005; Henriksen et } \\
\text { al., 1998; Loughrin et al., 2009; Martinez-Almela et al., 2003; Martinez-Almela and Barrera Marza, 2005; } \\
\text { Møller et al., 2007; Ndegwa, 2004; Rico et al., 2007; Szögi and Vanotti, 2007; Vanotti and Hunt, 1999; } \\
\text { Westerman and Bicudo, 2000; Westerman and Arogo Ogejo, 2005; Worley and Das, } 2000 .\end{array}$ \\
\hline Vibrating screen & 18 & 6 & 3 & 7 & Curnis, 2008; Pieters et al., 1999; Zhang and Westerman, 1997. \\
\hline
\end{tabular}

DM, dry matter; N, nitrogen; NH4, ammonium; P, phosphorous. 
The present study aims to: i) identify the effect of animal species, manure pre-treatment, use of additive and type of separator on the separation efficiency to distinguish different operational groups; and ii) for each of the identified groups, evaluate correlations of the separation efficiencies with the physical and chemical characteristics of the inlet slurries, using data available from published experiments on manure solid-liquid separation.

\section{Materials and methods}

\section{Database}

To define and validate the model, we first collected the necessary data. We conducted a bibliographical search that allowed us to collect papers about solid-liquid separation published in the last decade.

To obtain data expressed in the same units of measurement, the collected data were revised, if necessary, using the relationships between the relative density and the DM or nutrient concentrations in the raw slurry proposed by Piccinini et al. (1990).

Bibliographical data were collected in a database, organised as follows:

- Input related to the effluent: animal species (cattle and swine), effluent type (raw, digested and liquid from separation);

- Input related to the technology: separator type, use of chemical additives (additive yes/no);

- Slurry characteristics: DM concentration, N, P, potassium (K);

- Output: separation efficiency for DM (Eff. DM), nitrogen (Eff. N), phosphorus (Eff. P);

- References.

Operative data such as mesh size, centrifugal force or settling time were not used since none or few were available.

Table 3. Description of the 8 groups used for the elaborations.

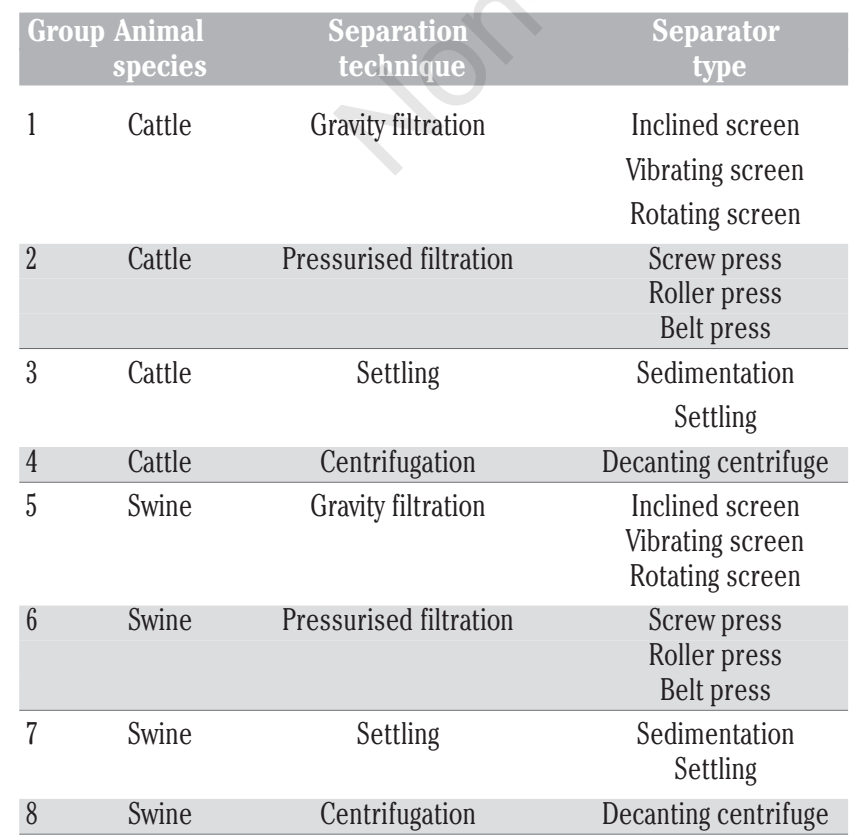

\section{Data collection}

The database is composed of data found through a bibliographical search. We collected 98 papers, published in the last decade. These mainly consisted of scientific papers, but also included proceedings from conferences, chapters from books, graduation theses and publications by universities and public institutions.

Hence, it is worth noting that data concerning experiments were gathered for a different purpose, so the studies are rather heterogeneous and not completely comparable. Furthermore, the separation efficiencies are calculated using different equations, affecting data elaboration. Most studies contained information about the DM concentration of input slurry but few had information about the considered separation efficiencies. In fact, some papers did not report the separation indexes, but did report the DM and nutrient concentrations in the solid and liquid fractions. Other papers did not give any information about the separation efficiencies, but provided nutrient concentrations of the input slurry and of the final products. Since there are different equations to calculate separation efficiency, we did not calculate separation efficiencies and, therefore, the data were not used in the analysis. In some cases, articles by the same authors referred to the same experiments. After this further selection, 60 publications were used (Table 2). The collected data were revised, if necessary, so as to be expressed in the same units of measurement. Finally, they were uploaded onto the database ( $\mathrm{n}=482$ observations).

\section{Data processing}

The SPSS 18.0 statistical package (IBM Corp., Armonk, NY, USA) was used to analyse the collected data.

Mean efficiency and variability for different categorical variables (animal species, effluent type, use of flocculants, separator type) were analysed by mean of error and bar plots were then produced. In this case, error bars represent the double standard error mean of separation efficiencies for DM, N and P. This analysis allowed us to identify the variables, which mainly affect separation efficiency, and to indicate if their means differed.

\section{Definition of relationships and model validation}

To define the correlations of the separation efficiencies with the physical and chemical characteristics of the inlet slurries, a regression analysis was performed using $\mathrm{DM}, \mathrm{N}, \mathrm{P}$ and $\mathrm{K}$ of the raw slurries as independent variables.

Model definition and validation was carried out on each of the groups using two methods:

- Random: using the SPSS 18.0 statistical package (IBM Corp.), the database was first divided into the identified groups. Each dataset was then randomly split into two fractions of $70 \%$ and $30 \%$ of observations, respectively (Preece et al., 2009). The first observations were used to define linear regressions that allowed us to model the relationships between the separation efficiencies and the DM concentration, distinguishing data through the presence or absence of chemical additives. Data sets containing $30 \%$ of the observations were used for model validation.

- Crossvalidation: the leave-one-out crossvalidation was performed using Unscrambler ${ }^{\odot} X$ 10.0.1 software (CAMO Software, Oslo, Norway) (Soriano-Disla et al., 2010) that was applied to each group.

For every regression, we calculated the coefficient of determination $\left(r^{2}\right)$ and the significance values. For crossvalidation, the coefficients of determination for calibration ( $\left.\mathrm{r}^{2} \mathrm{cal}\right)$ and validation $\left(\mathrm{r}^{2} \mathrm{val}\right)$ were calculated.

Finally, for every validation method, the reliability of predictions and their deviation from observed values were analysed both graphically and by means of error calculations. In particular, we calculated 
the root mean squared error (RMSE) and the relative root mean squared error (RRMSE):

$$
\begin{aligned}
& \text { RMSE }=\left[n^{-1} \sum_{i=1}^{n}\left(P_{i}-O_{i}\right)^{2}\right]^{1 / 2} \\
& \text { RRMSE }=\left(R M S E /_{\bar{O}}\right) \cdot 100
\end{aligned}
$$

where $n$ is the number of data used, $P_{i}$ are the predicted values, $O_{i}$ are the observed values and $\bar{O}$ is the mean of the observed data.

RMSE evaluates the model's accuracy as the difference between predicted and measured values, and it indicates the fitting's absolute mean error, while RRMSE shows the magnitude of the error. They were used to quantify model accuracy and to compare between them.

\begin{tabular}{|c|c|c|c|c|c|c|c|}
\hline Group & Additive & Efficiency (\%) & N. & Min & Max & Mean & Std. Dev. \\
\hline \multicolumn{8}{|l|}{1} \\
\hline Cattle gravity filtration & $\begin{array}{c}\text { Without } \\
\text { With }\end{array}$ & $\begin{array}{c}\text { DM } \\
N \\
P \\
\text { DM } \\
N \\
P\end{array}$ & $\begin{array}{l}35 \\
11 \\
11 \\
31 \\
41 \\
41\end{array}$ & $\begin{array}{c}6.00 \\
8.30 \\
12.10 \\
63.00 \\
14.00 \\
16.30\end{array}$ & $\begin{array}{l}71.70 \\
49.20 \\
62.80 \\
95.70 \\
86.00 \\
99.00\end{array}$ & $\begin{array}{l}32.26 \\
28.21 \\
35.46 \\
81.99 \\
51.97 \\
66.86\end{array}$ & $\begin{array}{l}16.43 \\
14.26 \\
16.56 \\
11.52 \\
16.00 \\
26.22\end{array}$ \\
\hline $\begin{array}{l}2 \\
\text { Cattle pressurised filtration }\end{array}$ & Without & $\begin{array}{c}\text { DM } \\
N \\
\text { P }\end{array}$ & $\begin{array}{l}36 \\
22 \\
22\end{array}$ & $\begin{array}{l}4.34 \\
3.97 \\
5.72\end{array}$ & $\begin{array}{l}77.80 \\
39.28 \\
73.70\end{array}$ & $\begin{array}{l}40.17 \\
17.25 \\
31.44\end{array}$ & $\begin{array}{l}16.69 \\
10.48 \\
20.57\end{array}$ \\
\hline \multicolumn{8}{|l|}{3} \\
\hline Cattle settling & $\begin{array}{c}\text { Without } \\
\text { With }\end{array}$ & $\begin{array}{c}\text { DM } \\
N \\
P \\
D M \\
N \\
P\end{array}$ & $\begin{array}{l}11 \\
11 \\
11 \\
44 \\
60 \\
61\end{array}$ & $\begin{array}{c}18.10 \\
1.60 \\
13.50 \\
29.30 \\
3.71 \\
16.30\end{array}$ & $\begin{array}{l}64.90 \\
40.00 \\
61.40 \\
92.80 \\
74.00 \\
91.70\end{array}$ & $\begin{array}{l}44.58 \\
20.25 \\
40.24 \\
78.38 \\
40.25 \\
66.05\end{array}$ & $\begin{array}{l}17.51 \\
11.59 \\
16.45 \\
11.59 \\
14.39 \\
20.17\end{array}$ \\
\hline $\begin{array}{l}4 \\
\text { Cattle centrifugation }\end{array}$ & Without & $\begin{array}{c}\text { DM } \\
N \\
P\end{array}$ & $\begin{array}{l}11 \\
11 \\
11\end{array}$ & $\begin{array}{l}53.50 \\
20.30 \\
45.50\end{array}$ & $\begin{array}{l}69.10 \\
49.12 \\
93.80\end{array}$ & $\begin{array}{l}59.84 \\
28.64 \\
71.84\end{array}$ & $\begin{array}{c}5.61 \\
7.42 \\
16.64\end{array}$ \\
\hline \multicolumn{8}{|l|}{5} \\
\hline Swine gravity filtration & $\begin{array}{c}\text { Without } \\
\text { With }\end{array}$ & $\begin{array}{c}\text { DM } \\
N \\
P \\
D M \\
N \\
P\end{array}$ & $\begin{array}{c}21 \\
15 \\
12 \\
0 \\
7 \\
15\end{array}$ & $\begin{array}{l}3.00 \\
3.50 \\
3.00 \\
\\
\\
13.00 \\
21.00\end{array}$ & $\begin{array}{l}58.70 \\
42.00 \\
46.50 \\
\\
35.00 \\
80.30\end{array}$ & $\begin{array}{l}26.75 \\
16.34 \\
17.55 \\
\\
\\
25.71 \\
60.37\end{array}$ & $\begin{array}{c}16.86 \\
11.67 \\
14.11 \\
\\
\\
8.24 \\
18.16\end{array}$ \\
\hline $\begin{array}{l}6 \\
\text { Swine pressurised filtration }\end{array}$ & $\begin{array}{c}\text { Without } \\
\text { With }\end{array}$ & $\begin{array}{c}\text { DM } \\
N \\
P \\
\text { DM } \\
N \\
P\end{array}$ & $\begin{array}{c}28 \\
25 \\
27 \\
4 \\
6 \\
6\end{array}$ & $\begin{array}{c}5.50 \\
0.83 \\
7.00 \\
38.10 \\
13.11 \\
53.97\end{array}$ & $\begin{array}{l}68.25 \\
33.50 \\
73.70 \\
79.37 \\
79.50 \\
90.48\end{array}$ & $\begin{array}{c}31.01 \\
9.34 \\
25.33 \\
54.40 \\
38.16 \\
75.94\end{array}$ & $\begin{array}{c}18.94 \\
8.47 \\
18.37 \\
18.50 \\
29.61 \\
14.26\end{array}$ \\
\hline \multicolumn{8}{|l|}{7} \\
\hline Swine settling & $\begin{array}{c}\text { Without } \\
\text { With }\end{array}$ & $\begin{array}{c}\mathrm{DM} \\
\mathrm{N} \\
\mathrm{P} \\
\mathrm{DM} \\
\mathrm{N} \\
\mathrm{P}\end{array}$ & $\begin{array}{l}3 \\
0 \\
0 \\
11 \\
15 \\
14\end{array}$ & $\begin{array}{l}34.00 \\
16.10 \\
70.00\end{array}$ & $\begin{array}{l}87.00 \\
58.30 \\
91.30\end{array}$ & $\begin{array}{l}65.57 \\
37.77 \\
81.44\end{array}$ & $\begin{array}{c}16.15 \\
14.76 \\
8.53\end{array}$ \\
\hline $\begin{array}{l}8 \\
\text { Swine centrifugation }\end{array}$ & Without & $\begin{array}{c}\mathrm{DM} \\
\mathrm{N} \\
\mathrm{P} \\
\mathrm{DM} \\
\mathrm{N} \\
\mathrm{P}\end{array}$ & $\begin{array}{l}46 \\
45 \\
45 \\
12 \\
12 \\
12\end{array}$ & $\begin{array}{c}8.00 \\
7.00 \\
26.00 \\
47.00 \\
17.00 \\
54.00\end{array}$ & $\begin{array}{l}70.40 \\
35.50 \\
90.95 \\
76.00 \\
48.00 \\
88.00\end{array}$ & $\begin{array}{l}48.53 \\
20.84 \\
66.57 \\
57.83 \\
32.83 \\
71.00\end{array}$ & $\begin{array}{l}15.29 \\
7.22 \\
13.34 \\
11.19 \\
11.65 \\
11.82\end{array}$ \\
\hline
\end{tabular}

Table 4. Descriptive statistics of each group for the entire database divided by the use of chemicals.

DM, dry matter; N, nitrogen; P, phosphorous; Std. Dev, standard deviation. 


\section{Results and discussion}

\section{Data analysis}

\section{Factors influencing separation efficiency}

This analysis aimed to identify the categorical variables mainly affecting the separation efficiencies. In particular, we considered the separation efficiencies for DM, $\mathrm{N}$ and $\mathrm{P}$, expressed as functions of ani- mal species, effluent type, use of additives and separator type. When the separation efficiencies are grouped according to species (Figure 1A), mean values have significantly different variations for all the separation efficiencies considered. Specifically, the separation efficiencies for cattle slurries are higher, meaning more DM, N and P are in the solid fraction at separation of cattle slurry rather than in swine slurry. This result agrees with previous findings (Peters et al., 2011).

The mean values also present different variations when separation efficiencies are classified by the use of chemical additives (Figure 1B).

Table 5. Correlation equations, $\mathbf{r}^{2}$ and significance $(F)$ values of regressions achieved by the random method. For each group, values are distinguished by the use of chemical additives.

\begin{tabular}{|c|c|c|c|c|c|c|}
\hline Group & Additive & N. & $\begin{array}{c}\text { Random } \\
\text { Separation efficiency (\%) }\end{array}$ & Correlation equation $^{\circ}$ & $r^{2}$ & $\mathbf{F}$ \\
\hline \multicolumn{7}{|l|}{1} \\
\hline \multirow{6}{*}{ Cattle gravity filtration } & Without & 9 & DM & $0.483 * \mathrm{DM}+24.39$ & 0.35 & $* * *$ \\
\hline & & 6 & $\mathrm{~N}$ & $0.16^{*} \mathrm{DM}+27.5$ & 0.2 & n.s. \\
\hline & & 6 & $\mathrm{P}$ & $-0.02 * \mathrm{DM}+35.1$ & 0 & n.s. \\
\hline & With & 22 & DM & $0.32 * \mathrm{DM}+81.6$ & 0.012 & n.s. \\
\hline & & 27 & $\mathrm{~N}$ & $-0.5 * \mathrm{DM}+52.5$ & 0.05 & n.s. \\
\hline & & 27 & $\mathrm{P}$ & $-2.034 * \mathrm{DM}+109.05$ & 0.88 & $* * *$ \\
\hline \\
\hline Cattle pressurised filtration & Without & $\begin{array}{l}26 \\
18\end{array}$ & $\begin{array}{l}\mathrm{DM} \\
\mathrm{N}\end{array}$ & $\begin{array}{c}0.506 * \mathrm{DM}+8.966 \\
0.30 * \mathrm{DM}-3.49\end{array}$ & $\begin{array}{l}0.69 \\
0.34\end{array}$ & $\begin{array}{c}* * * \\
*\end{array}$ \\
\hline & & 18 & $\mathrm{P}$ & $0.51 * \mathrm{DM}-2.48$ & 0.25 & n.s. \\
\hline \multicolumn{7}{|l|}{3} \\
\hline \multirow[t]{6}{*}{ Cattle settling } & Without & 7 & DM & $1.104 * \mathrm{DM}+18.33$ & 0.43 & n.s \\
\hline & & 7 & & $0.556 * \mathrm{DM}+6.907$ & 0.17 & n.s. \\
\hline & & 7 & & $0.62 * \mathrm{DM}+17.235$ & 0.23 & n.s. \\
\hline & With & 31 & DM & $-0.77 * \mathrm{DM}+89.23$ & 0.48 & $* * *$ \\
\hline & & 40 & $\mathrm{~N}$ & $0.067 * \mathrm{DM}+36.1$ & 0.004 & n.s. \\
\hline & & 41 & $\mathrm{P}$ & $-1.13^{*} \mathrm{DM}+91.53$ & 0.58 & $* * *$ \\
\hline \multirow{4}{*}{$\begin{array}{l}4 \\
\text { Cattle centrifugation }\end{array}$} & & & & & & \\
\hline & Without & 7 & DM & $0.044 * \mathrm{DM}+57.923$ & 0.05 & n.s. \\
\hline & & 7 & $\mathrm{~N}$ & $0.181 * \mathrm{DM}+22.556$ & 0.33 & n.s. \\
\hline & & 7 & $\mathrm{P}$ & $-0.4 * \mathrm{DM}+86.1$ & 0.5 & $*$ \\
\hline \multicolumn{7}{|l|}{5} \\
\hline \multirow[t]{6}{*}{ Swine gravity filtration } & Without & 8 & DM & $-0.2 * \mathrm{DM}+25.77$ & 0.06 & n.s. \\
\hline & & 5 & $\mathrm{~N}$ & $0.37 * \mathrm{DM}+6.11$ & 0.4 & n.s. \\
\hline & & 5 & $\mathrm{P}$ & $0.57 * \mathrm{DM}+1.2$ & 0.15 & n.s. \\
\hline & & 0 & DM & n.a & n.a & n.a. \\
\hline & & 5 & $\mathrm{~N}$ & n.a & n.a & n.a. \\
\hline & & 5 & $P$ & n.a & n.a & n.a. \\
\hline \multicolumn{7}{|l|}{6} \\
\hline \multirow[t]{3}{*}{ Swine pressurised filtration } & Without & 15 & DM & $0.55^{*} \mathrm{DM}+11.44$ & 0.32 & $*$ \\
\hline & & 15 & $\mathrm{~N}$ & $0.34 *$ DM-1.89 & 0.42 & $*$ \\
\hline & & 15 & $\mathrm{P}$ & $0.15 * \mathrm{DM}+16.5$ & 0.04 & n.s. \\
\hline \multicolumn{7}{|l|}{7} \\
\hline \multirow[t]{6}{*}{ Swine settling } & Without & 2 & DM & $-0.9 * \mathrm{DM}+70.8$ & 0.99 & n.s. \\
\hline & & 0 & $\mathrm{~N}$ & n.a & n.a & n.a \\
\hline & & 0 & $\mathrm{P}$ & n.a. & n.a & n.a. \\
\hline & With & 6 & DM & $1.33 * \mathrm{DM}+38.89$ & 0.68 & $*$ \\
\hline & & 6 & $\mathrm{~N}$ & $0.763 * \mathrm{DM}+18.434$ & 0.48 & n.s. \\
\hline & & 5 & $\mathrm{P}$ & $0.3^{*} \mathrm{DM}+77.976$ & 0.21 & n.s. \\
\hline 8 & & & & & & \\
\hline \multirow[t]{6}{*}{ Swine centrifugation } & Without & 32 & DM & $0.5^{*} \mathrm{DM}+28.97$ & 0.64 & $* * *$ \\
\hline & & 31 & $\mathrm{~N}$ & $0.15^{*} \mathrm{DM}+16.14$ & 0.26 & $* *$ \\
\hline & & 31 & $\mathrm{P}$ & $0.34 * \mathrm{DM}+54.12$ & 0.45 & *** \\
\hline & With & 8 & DM & $0.46 * \mathrm{DM}+29.55$ & 0.05 & n.s. \\
\hline & & 8 & $\mathrm{~N}$ & $0.13 * \mathrm{DM}+16.15$ & 0.05 & n.s. \\
\hline & & 8 & $\mathrm{P}$ & $0.30 * \mathrm{DM}+53.44$ & 0.07 & n.s. \\
\hline
\end{tabular}

DM, dry matter; $\mathrm{N}$, nitrogen; P, phosphorous; n.s., not significant; n.a., not available. ${ }^{\circ} \mathrm{DM}, \mathrm{DM}$ concentration in the input slurry $\left(\mathrm{gL}^{-1)} ; * * * * * * *\right.$, significant correlations at $\mathrm{P}<0.05,0.01,0.001$, respectively. 
As expected, flocculants improve the separation efficiencies and it is a relevant predictive variable. Digestion and removal of solids with separation reduce the DM content of the liquid fraction and increase relative content of the dissolved total ammoniacal nitrogen in the nitrogen pool. Therefore, effects on the separation index could be expected. However, considering separation efficiency for DM (Figure 1C), means having different variations only for separated slurry, whereas the three effluent types (digested, raw and liquid from separation) do not present different variations in the means for the separation efficiency of $\mathrm{N}$ and $\mathrm{P}$. Therefore, we could not confirm that the effluent type statistically affects the separation efficiencies. This absence of a significant statistical difference could be due to the fact that manures from different origins are included in the different pool; they are not, therefore, suitable for definitively ruling out a correlation/ variation. In conclusion, from this analysis, the categorical variables, which mainly affect separation efficiencies, are animal species, use of chemical additives and separator type.

Table 6. Correlation equations, $\mathbf{r}^{2}$ and significance $(F)$ values of regressions achieved by the cross-validation method. For each group, values are distinguished by the use of chemical additives.

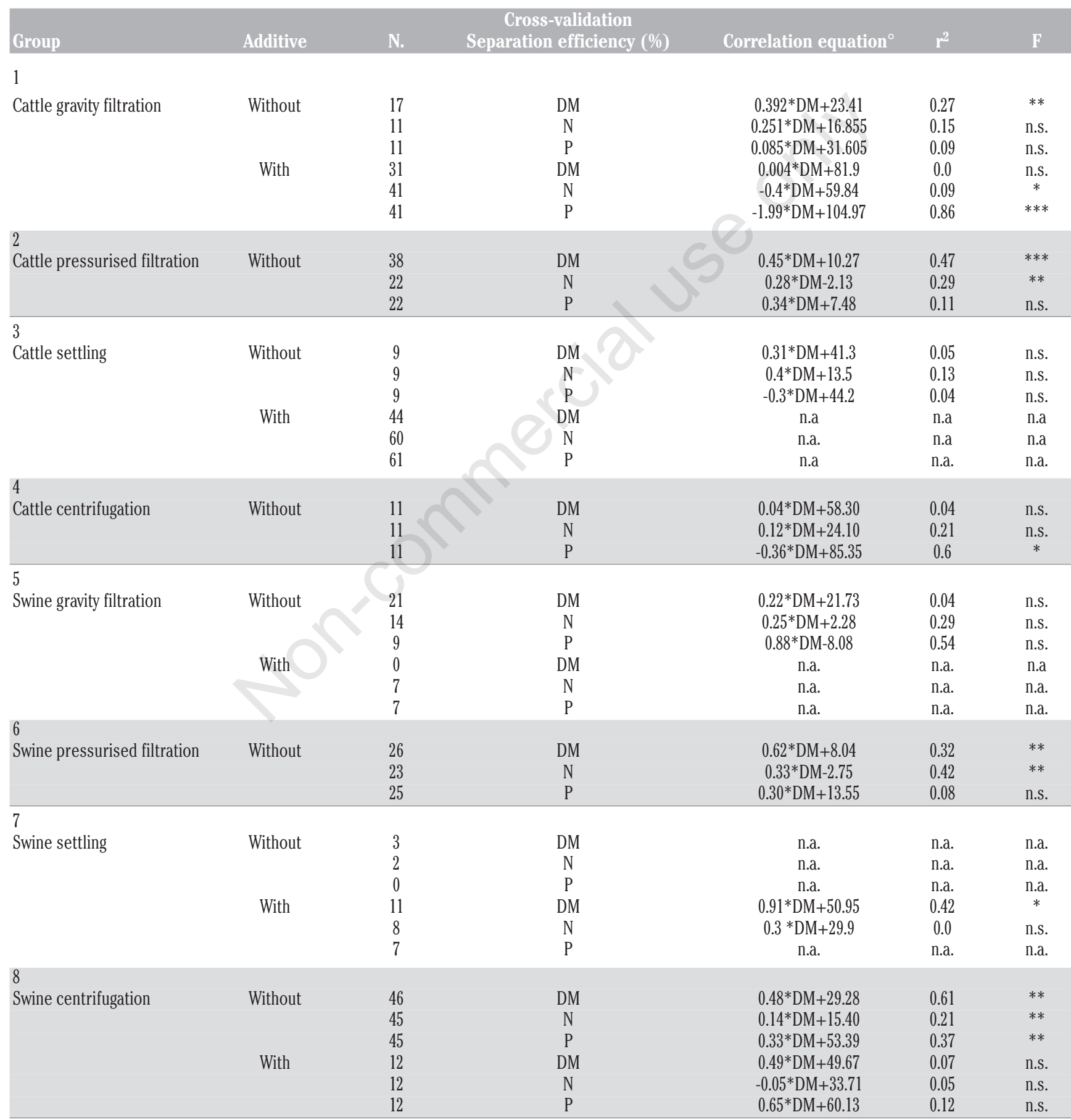

DM, dry matter; $\mathrm{N}$, nitrogen; P, phosphorous; n.s., not significant; n.a., not available. ${ }^{\mathrm{D} M}$, DM concentration in the input slurry (gL-); ${ }^{*},{ }^{* *},{ }^{* * *}$, significant correlations at $\mathrm{P}<0.05,0.01,0.001$, respectively. 


\section{Separator grouping}

Some separator types behave similarly in accordance with their functioning characteristics, as described above (Table 1). Therefore, separator types were grouped according to their construction and operating characteristics (gravity filtration, pressurised filtration, settling and centrifugation), taking into account the results of dispersion and error bar plots. Thus, separation devices were divided in 8 groups: 4 for cattle slurry and 4 for swine slurry (Table 3 ).

Finally, for every group, data were distinguished by the presence or absence of chemical additives. Since some separator types are not used with chemical additives in the collected experiments (groups 2 and 4), 14 subgroups were obtained.

For each identified group, descriptive statistics were calculated (Table 4). It is clear in Table 4 that, for some groups, more data are available (e.g. groups 2 and 8 ). For every group, each variable has a different number of observations; there were more observations for separation efficiencies achieved without chemical additives, except for sedimentation (groups 3 and 7). Considering all groups, some separation efficiencies present few data. Furthermore, for each cluster, the data present a high range of variation, particularly without flocculants.

The order of the separation efficiencies for DM, $\mathrm{N}$ and $\mathrm{P}$ within swine and cattle slurry are equivalent, i.e. pressurised filtration $<$ gravity filtration < centrifugation (with additive) < settling (with additive). Hence, sedimentation techniques are superior to filtration. Applying filtration without chemical additives is the least effective technique. Application of additives causes the most efficient separation. Without chemical additives, sedimentation techniques are superior to filtration, as also indicated in the error bar plots. Gravity filtration without chemical additives requires large mesh so only large particles are retained in the solid fraction. Settling under optimal conditions, i.e. high force applied and long retention time, also cause retention of small particles in the solid fraction. This is supported by previous findings (Møller et al., 2002).

The order of efficiency of the separator types for $\mathrm{N}$ and $\mathrm{P}$ separation efficiencies was similar to DM separation efficiency. This is supported by the fact that $\mathrm{N}$, and particularly $\mathrm{P}$, are associated with the particles (Christensen et al., 2009).
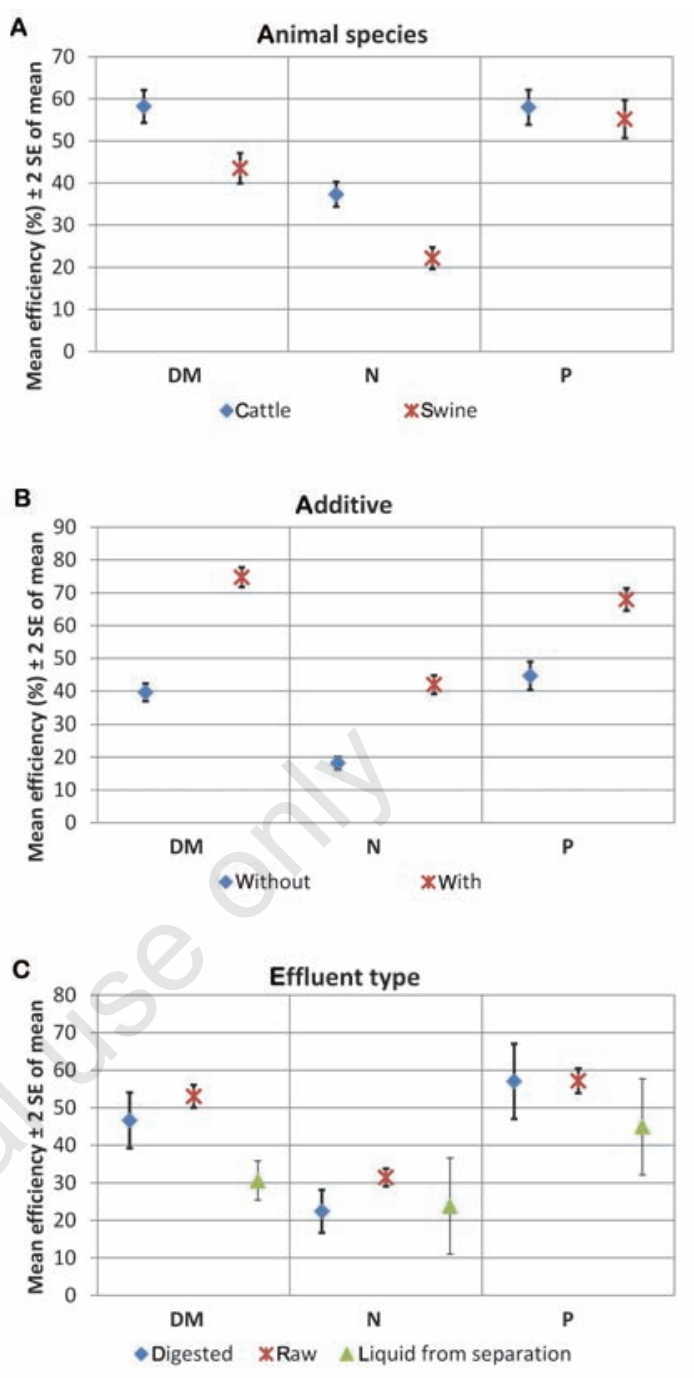

Figure 1. Error bar plots of separation efficiencies for dry matter, nitrogen and phosphorous grouped by species $(\mathrm{A})$, use of chemical additives (B) and effluent type (C).

Table 7. Root mean squared error and relative root mean squared error values for significant equations.

\begin{tabular}{|c|c|c|c|c|c|c|}
\hline \multirow[t]{2}{*}{ Group } & \multirow[t]{2}{*}{ Additive } & \multirow[t]{2}{*}{ Efficiency (\%) } & \multicolumn{2}{|c|}{ RMSE } & \multicolumn{2}{|c|}{ RRMSE (\%) } \\
\hline & & & Random & Cross-validation & Random & Cross-validation \\
\hline 1 Cattle gravity filtration & $\begin{array}{l}\text { Without } \\
\text { With }\end{array}$ & $\begin{array}{c}\mathrm{DM} \\
\mathrm{P}\end{array}$ & $\begin{array}{l}17.29 \\
17.73\end{array}$ & $\begin{array}{l}14.26 \\
12.19\end{array}$ & $\begin{array}{l}53.60 \\
26.52\end{array}$ & $\begin{array}{l}44.20 \\
18.23\end{array}$ \\
\hline $\begin{array}{l}2 \\
\text { Cattle pressurised filtration }\end{array}$ & Without & $\begin{array}{c}\text { DM } \\
\mathrm{N}\end{array}$ & $\begin{array}{l}15.66 \\
8.65\end{array}$ & $\begin{array}{c}12.38 \\
9.06\end{array}$ & $\begin{array}{l}38.98 \\
50.14\end{array}$ & $\begin{array}{l}30.82 \\
52.52\end{array}$ \\
\hline $\begin{array}{l}4 \\
\text { Cattle centrifugation }\end{array}$ & Without & $P$ & 15.93 & 14.00 & 24.38 & 19.49 \\
\hline $\begin{array}{l}6 \\
\text { Swine pressurised filtration }\end{array}$ & Without & $\begin{array}{c}\text { DM } \\
N\end{array}$ & $\begin{array}{l}15.60 \\
4.87\end{array}$ & $\begin{array}{l}15.22 \\
6.94\end{array}$ & $\begin{array}{l}50.31 \\
52.14\end{array}$ & $\begin{array}{l}49.08 \\
74.30\end{array}$ \\
\hline $\begin{array}{l}7 \\
\text { Swine settling }\end{array}$ & With & $\mathrm{DM}$ & 22.02 & 15.68 & 33.13 & 23.91 \\
\hline $\begin{array}{l}8 \\
\text { Swine centrifugation }\end{array}$ & Without & $\begin{array}{c}\text { DM } \\
\mathrm{N} \\
\mathrm{P}\end{array}$ & $\begin{array}{l}7.67 \\
5.83 \\
8.52\end{array}$ & $\begin{array}{c}9.69 \\
6.47 \\
10.73\end{array}$ & $\begin{array}{l}15.80 \\
27.98 \\
12.80\end{array}$ & $\begin{array}{l}19.97 \\
31.05 \\
16.12\end{array}$ \\
\hline
\end{tabular}

DM, dry matter; N, nitrogen; P, phosphorous; RMSE, root mean squared error; RRMSE, relative root mean squared error. 


\section{Correlation definition}

Using the methods described above, we carried out the regressions for model definition (random and crossvalidation). In particular, we defined regressions that identify the relationships between the separation efficiencies for DM, N and P with the DM, N, P and K concentration of the slurry. DM was the only parameter included in the regression model used and, therefore, results are shown using only this parameter as independent variable.

As shown in Table 3, some separator types, corresponding to groups 2 (cattle slurry/pressurised filtration) and 4 (cattle slurry/centrifugation), are not used with chemical additives. Furthermore, for group 6 (swine slurry/pressurised filtration), data for separation indexes achieved with chemicals refer only to belt presses and are highly variable. For this reason, only regressions for separation efficiencies of swine manure treated by pressurised filtration without additives were calculated.

Tables 5 and 6 present the correlation equations, and their $\mathrm{r}^{2}$ and significance (F) values obtained applying the random and crossvalidation methods, respectively. In some cases, the methods used did not achieve significant regressions for all the separation efficiencies because of the lack of data or because of the presence of some anomalous values for the DM concentration of the input slurry.

After model definition, regressions were validated using plots and error calculation. In particular, we calculated the RMSE error and the RRMSE only for regressions that resulted significant for both random and crossvalidation methods (Table 7). In most cases, the RRMSE values are below $50 \%$ for both random and crossvalidation methods.

For solid-liquid separation of cattle slurry by gravity filtration (group 1) without using chemical additives, only the correlations for the DM separation efficiencies were significant. However, the separation efficiency for DM is not entirely correlated to the input DM concentration; in this case, the measured values are highly variable and, therefore, the RRMSEs are large for both random and crossvalidation models. Hence, a larger amount of experimental data could allow us to achieve multiple linear regression lines depending not only on the DM concentration of the input slurry, but also on other criteria that affect the separation efficiency, such as mesh size.

Using additives, only the regressions for the separation efficiency of $P$ were significant. The random and the crossvalidation models showed a decreasing trend, matching that of the data.

Overall, for cattle manure treated by pressurised filtration without chemical additives, the random and the crossvalidation regressions were significant only for DM and N separation indexes. However, RRMSE for N separation efficiency was high (Table 7).

There are few and variable measured data related to the P separation efficiency for the separation of cattle slurry by centrifugation without chemical additives.

As for cattle slurry, only the separation efficiencies for DM and $\mathrm{N}$ present significant regressions for swine slurry separated with pressurised filtration without additives. Separation efficiencies of DM data are very variable and so, even though the random and crossvalidation models are similar, the regression error is greater. Generally, the separation efficiency of DM and $\mathrm{N}$ for pressurised filtration of cattle and swine slurry (groups 2 and 6) are both correlated to the DM content of the input slurry. Of all the separator types, these pressurised filtration separators result in the fewest of the minor particles being retained in the solid fraction, which may be why this correlation is so simple and, therefore, reaches significance.

The separation efficiency for DM of the solid-liquid separation of swine manures by sedimentation using flocculants presents few data showing a clear tendency and has a good fit in both of the two models. For the separation of swine slurry by centrifugation, only the separation efficiencies for DM, $\mathrm{N}$ and $\mathrm{P}$ without the addition of flocculants present significant regressions. Separation efficiencies for $\mathrm{DM}, \mathrm{N}$ and $\mathrm{P}$ were very similar.
Generally, we did not find significant correlations for separation efficiencies obtained using flocculants, except for groups 1 and 7 . In general, correlations may be complicated by the applied flocculation treatments, which vary greatly between the different experiments. Therefore, it is necessary to take into account the chemical applied and the added dose relative to the optimal chemical dose.

\section{Conclusions}

The analysis allowed us to distinguish several technological and operational conditions that affect separation efficiency. The most relevant characteristic of the input slurry is DM. The main variables affecting separation efficiency are species, use of additives and separator type.

For 7 of the 14 subgroups, it was possible to define and validate the predictive models. These present RRMSEs that are less than $50 \%$ and could, therefore, be implemented in a decision support tool to identify the most effective treatment option according to the farmer's needs. For the remaining separation technologies and operative conditions, most of which include the use of flocculants, more data are needed to define and validate empirical predictive models.

Except for settling, most of the correlations related to the use of additives were not significant. This is due to the wide variety of additives used in the different experiments. In fact, the different types of chemicals and their dosages affect the separation efficiencies in different ways and to different degrees. Therefore, experiments concerning the use of flocculants are often not comparable.

With regard to $\mathrm{N}$ separation efficiency, only pressurised filtration was significantly correlated for both cattle and pig slurry, while centrifugation was significant only for pig manure.

More detailed predictive models might be defined only if uniform and complete sets of data are available. In fact, bibliographic data derive from different kinds of experiments that often had different aims and could not be compared. Furthermore, they seldom include all the relevant information required to evaluate efficiency variations (pressure, mesh size, flow rate).

Therefore, more precise and physically-based models should be defined with the support of specific studies in order to predict separation efficiencies in practical conditions.

\section{References}

Balsari P., Gioelli F., Dinuccio E., Santoro E. 2006. Monitoraggio degli impianti di separazione solido liquido dei liquami di suini e di bovini. Relazione finale della ricerca. Università di Torino, Torino, Italy.

Barrow J.T., Van Horn H.H., Anderson D.L., Nordstedt R.A. 1997. Effects of Fe and $\mathrm{Ca}$ additions to dairy wastewaters on solids and nutrient removal by sedimentation. Appl. Eng. Agric. 13:259-67.

Bertora C., Alluvione F., Zavattaro L., van Groeningen J.W, Velthof G., Grignani C. 2008. Pig slurry treatment modifies slurry composition, $\mathrm{N}_{2} \mathrm{O}$, and $\mathrm{CO}_{2}$ emissions after soil incorporation. Soil Biol. Biochem. 40:1999-2006.

Brito L.M., Coutinho J., Smith S.R. 2008. Methods to improve the composting process of the solid fraction of dairy cattle slurry. Bioresource Technol. 99:8955-8960.

Burns R.T., Moody L.B. 2003. Development of a standard method for testing mechanical manure solids separators. ASAE Annual International Meeting, July 27-30, Las Vegas, Nevada, USA.

Burton C.H. 2007. The potential contribution of separation technologies to the management of livestock manure. Livest. Sci. 112:208-16. 
Burton C.H., Turner C. 2003. Manure management - Treatment strategies for sustainable agriculture. $2^{\text {nd }}$ Ed. Silsoe Research Institute, Bedford, UK.

Campos E., Almirall M., Mtnez-Almela J., Flotats X. 2002. Anaerobic digestion of solid fraction of pig slurry. Proc. of Int. Symposium on Anaerobic Digestion of Solid Waste, 1-8 September, Munich, Germany.

Campos E., Almirall M., Mtnez-Almela J., Palatsi J., Flotats X. 2008. Feasibility study of the anaerobic digestion of dewatered pig slurry by means of polyacrylamide. Bioresource Technol. 99:387-95.

Chastain J.P. 2009. Field evaluation of a two-stage liquid-solid separation system at a California dairy. ASABE Annual International Meeting, June 21-24, Reno, Nevada, USA.

Chastain J.P., Lucas W.D., Albrecht J.E., Pardue J.C., Adams III J., Moore K.P. 2001a. Removal of solids and major plants nutrients from swine manure using a screw press separator. Appl. Eng. Agric. 17:355-63.

Chastain J.P., Vanotti M.B. 2003. Correlation equations to predict the solids and plant nutrient removal efficiencies for gravity settling of swine manure. Proc. 9 $9^{\text {th }}$ Int. Symp. Animal Agr. Food Proces. Wastes, 12-15 October, Research Triangle Park, North Carolina, USA, 487-95.

Chastain J.P., Vanotti M.B., Wingfield M.M. 2001b. Effectiveness of liquid-solid separation for treatment of flushed dairy manure: a case of study. Appl. Eng. Agric. 17:343-54.

Christensen M.L., Hjorth M., Keiding K. 2009. Characterization of pig slurry with reference to flocculation and separation. Water Res. 43:773-83

Converse J.C., Karthikeyan K.G. 2004. Nutrient and solids separation of flushed dairy manure by gravity settling. Appl. Eng. Agric. 20:503-7.

Converse J.C., Koegel R.G., Straub R.J. 2000. Nutrient separation of dairy manure. Proc. $8^{\text {th }}$ Int. Symp. Animal Agr. Food Proces. Wastes, October 9-11, Des Moines, Iowa, USA, 118-31.

Curnis S. 2008. Analisi della funzionalità di impianti per la separazione solido-liquido degli effluenti in aziende francesi e italiane di bovini da latte. Degree Diss., University of Milan.

Dinuccio E., Berg W., Balsari P. 2008. Gaseous emissions from the storage of untreated slurries and the fractions obtained after mechanical separation. Atmos. Environ. 42:2448-59.

Duarte E.A., Neto I., Queda C.C. 2001. An integrated waste management technology applied to a swine intensive production unit without available farmland. Technology Transfer. Proc. $9^{\text {th }}$ Int. Conf. "FAO ESCORENA network on recycling of agricultural, municipal and industrial residues in agriculture", September 6-9.Gargano, Italy, 175-9.

Fangueiro D., Coutinho J., Chadwick D., Moreira N., Trindade H. 2008a. Effect of cattle slurry separation on greenhouse gas and ammonia emissions during storage. J. Environ. Qual. 37:2332-1.

Fangueiro D., Pereira J., Chadwick D., Coutinho J., Moreira N., Trindade H. 2008b. Laboratory assessment of the effect of cattle slurry pre-treatment on organic $\mathrm{N}$ degradation after soil application and N20 and N2 emissions. Nutr. Cycl. Agroecosyst. 80:107-20.

Fangueiro D., Ribeiro H., Vasconcelos E., Coutinho J., Cabral F. 2009. Treatment by acidification followed by solid-liquid separation affects slurry and slurry fractions composition and their potential on N mineralization. Bioresource Technol. 100:4914-7.

Fangueiro D., Senbayran M., Trindade H., Chadwick D. 2008c. Cattle slurry treatment by screw press separation and chemically enhanced settling: effect on greenhouse gas emissions after land spreading and grass yield. Bioresource Technol. 99:7132-42.

Ford M., Flemming R. 2002. Mechanical solid liquid separation of livestock manure. Literature Review. Ridgetown College - University of Guelp, Ridgetown, Ontario, Canada.

Garcia M.C., Szögi A.A., Canotti M.B., Chastain J.P. 2007a. Solid-liquid separation of dairy manure with PAM and chitosan polymer. ASABE. International Symposium on Air Quality and Waste, September 16-19, Broomfield, Colorado, USA.

Garcia M.C., Szögi A.A., Vanotti M.B., Chastain J.P., Millner P.D. 2009. Enhanced solid-liquid separation of dairy manure with natural flocculants. Bioresource Technol. 100:5417-23.

Garcia M.C., Vanotti M.B., Szögi A.A. 2007b. Simultaneous separation of phosphorus sludge and manure solids with polymers. Trans. ASABE 50:2205-15.

Gonzàlez-Fernàndez C., Nieto-Diez P.P., Leòn-Cofreces C., GarcìaEncina C.A. 2008. Solids and nutrients removals from the liquid fraction of swine slurry through screening and flocculation treatment and influence of these processes on anaerobic biodegradability. Bioresource Technol. 99:6233-9.

Gooch C.A.P.E., Inglis S.F., Czymmek K.J. 2005. Mechanical solid-liquid manure separation: performance evaluation on four New York State dairy farms - A preliminary report. ASAE Annual International Meeting, July 17-20, Tampa, Florida, USA.

Hansen M.N., Kai P., Møller H.B. 2006. Effects of anaerobic digestion and separation of pig slurry on odor emission. Appl. Eng. Agric. 22:135-9.

Henriksen K., Berthelsen L., Matzen R. 1998. Separation of liquid pig manure by flocculation and ion exchange. Part 2: pilot-scale system. J. Agric. Eng. Res. 69:127-31.

Hill D.T., Baier J.W. 2000. Physical and chemical properties of screenedflushed pig slurry waste. J. Agric. Eng. Res. 77:441-8.

Hjorth M., Christensen K.V., Christensen M.L., Sommer S.G. 2010. Solid-liquid separation of animal slurry in theory and practice. A review. Agron. Sustain. Dev. 30: 153-180.

Hjorth M., Nielsen A.M., Nyord T., Hansen M.N., Nissen P., Sommer S.G. 2009. Nutrient value, odour emission and energy production of manure as influenced by anaerobic digestion and separation. Agron. Sustain. Dev. 29:329-38.

Kaparaju P.L.N., Rintala J.A. 2008. Effects of solid-liquid separation on recovering residual methane and nitrogen from digested cow manure. Bioresourche Technol. 99:120-7.

Karakashev D., Schmidt J.E., Angelidaki I. 2008. Innovative process scheme for removal of organic matter, phosphorus and nitrogen from pig manure. Water Res. 42:4083-90.

Karmakar S., Laguë C., Landry H. 2007. Integrated decision support system (DSS) for manure management: A review and perspective. Comput. Electron. Agr. 57:190-201.

Kunz A., Miele M., Steinmetz R.L.R. 2009. Advanced swine manure treatment and utilization in Brazil. Bioresource Technol. 100: $5485-9$.

Loughrin J.H., Vanotti M.B., Szögi A.A., Lovanh N. 2009. Evaluation of second-generation multistage wastewater treatment system for the removal of malodors from liquid swinw waste. J. Environ. Qual. $38: 1739-48$.

Loyon L., Guiziou F., Béline F., Peu P. 2006. Gasseous emissions $\left(\mathrm{NH}_{3}\right.$, $\mathrm{N}_{2} \mathrm{O}, \mathrm{CH}_{4}, \mathrm{CO}_{2}$ ) during pig slurry biological aerobic treatment and treatment by-product storages. Int. Congr. Series. 1293:299-302.

Marcato C.E., Pinelli E., Pouech P., Winterton P., Guiresse M. 2008. Particle size and metal distribution in anaerobically digested pig slurry. Bioresource Technol. 99:2340-8.

Martinez-Almela J., Barrera Marza J.M. 2005. SELCO-ECOPURIN® pig slurry treatment. Bioresource Technol. 96:223-8.

Martinez-Almela J., Barrera Marza J.M., Salmo Casals D., Lorenzo Navarro M. 2003. SELCO-ECOPURIN® separation technology for conversion of animal waste into added value products and energy. Proc. $9^{\text {th }}$ Int. Symp. Animal Agr. Food Proces. Wastes, October 12-15, Research Triangle Park, North Carolina, USA.

Melse R.W., Verdoes N. 2005. Evaluation of four farm-scale systems for the treatment of liquid pig manure. Biosyst. Eng. 92:47-57. 
22:185-93.

Meyer D., Ristow P.L., Lie M. 2007. Particle size and nutrient distribution in fresh dairy manure. Appl. Eng. Agric. 23:113-7.

Møller H.B., Hansen J.D., Sørensen C.A.G. 2007. Nutrient recovery by solid-liquid separation and methane productivity of solids. Trans. ASABE 50:193-200.

Møller H.B., Lund I., Sommer S.G. 2000. Solid-liquid separation of livestock slurry: efficiency and cost. Bioresource Technol. 74:223-9.

Møller H.B., Sommer S.G., Ahring B.K. 2002. Separation efficiency and particle size distribution in relation to manure type and storage conditions. Bioresource Technol. 85:189-96.

Ndegwa P.M. 2004. Solids separation enhances reduction of organic strength of swine manure subjected to aeration treatments. Trans. ASAE 47:1659-66.

Peters K., Hjorth M., Jensen L.S., Magid J. 2011. Carbon, nitrogen and phosphorus distribution in particle size-fractioned separated pig and cattle slurry. J. Environ. Qual. 40:224-32.

Petersen J., Sørensen P. 2008. Loss of nitrogen and carbon during storage of the fibrous fraction of separated pig slurry and influence on nitrogen availability. J. Agric. Sci. 146:403-13.

Petersen S.0., Sommer S.G., Béline F., Burton C., Dach J., Dourmad J.Y., Leip A., Misselbrook T., Nicholson F., Poulsen H.D., Provolo G., Søresen P., Vinnerås B., Weiske A., Bernal M.P., Böhm R., Juhàsz R., Mihelic R. 2007. Recycling of livestock manure in a whole-farm perspective. Livest. Sci. 112:180-91.

Piccinini S., Bortone G., Meglioli M. 1990. Valore fertilizzante dei liquami zootecnici: metodo rapido e semplice di misura. Genio Rurale 53:21-6.

Pieters J.G., Neukermans G.G.J., Colanbeen M.B.A. 1999. Farm-scale membrane filtration of sow slurry. J. Agric. Eng. Res. 73:403-9.

Preece S.L., Morgan C.L.S., Auvermann B. W., Wilke K., Heflin K. 2009. Determination of ash content in solid cattle manure with visible near-infrared diffuse reflectance spectroscopy. Trans. ASABE 52:609-14.

Rico J.L., Garcìa H., Rico C., Pérez N. 2006. Two-factor design coagulant/flocculant doses for solid-liquid separation of dairy manure. Environ. Technol. 27:143-51.

Rico J.L., Garcìa H., Rico C., Tejero I. 2007. Characterisation of solid and liquid fractions of dairy manure with regard to their component distribution and methane production. Bioresource Technol. 98:971-9.

Sørensen, C.G., Møller, H.B. 2006. Operational and economic modelling and optimization of mobile slurry separation. Appl. Eng. Agric.
Soriano-Disla J.M., Gòmez I., Guerrero C., Navarro-Pedreño J., GarcìaOrenes F. 2010. The potential of NIR spectroscopy to predict stability parameters in sewage sludge and derived compost. Geoderma. 158:93-100.

Svarovsky L. 1981. Solid-liquid separation ( $2^{\text {nd }}$ Ed.). Butterworths, Oxford, UK.

Szögi A.A., Vanotti M.B. 2007. Abatement of ammonia emissions from swine lagoons using polymer-enhanced solid-liquid separation. Appl. Eng. Agric. 23:837-45.

Tilche A., Bacilieri E., Bortone G., Malaspina F., Piccinini S., Stante L. 1999. Biological phosphorus and nitrogen removal in a full scale sequencing batch reactor treating piggery wastewaters. Water Sci. Technol. 40:199-206.

Vanotti M.B., Hunt P.G. 1999. Solids and nutrient removal from flushed manure using polyacrylamides. Trans. ASAE 42:1833-40.

Vanotti M.B., Rashash D.M.C., Hunt P.G. 2002. Solid-liquid separation of flushed swine manure with PAM: effect of wastewater strength. Trans. ASAE 45:1959-69.

Walker P., Kelley T. 2005. Comparison of a static gravity screen-roll press combination separator to a PAM-assisted gravity belt thickener system for swine waste slurry solids separation. Bioresource Technol. 96:571-6.

Westerman P.W., Arogo Ogejo J. 2005. Centrifuge solids/liquid separation of swine flushed manure and lagoon sludge. ASAE Annual International Meeting, July 17-20, Tampa, Florida, USA.

Westerman P.W., Bicudo J.R. 2000. Tangential flow separation and chemical enhancement to recover swine manure solids, nutrients and metals. Bioresource Technol. 73:1-11.

Worley J.W., Das K. 2000. Swine manure solids separation and composting using alum. Appl. Eng. Agric. 16:555-61.

Wright W.F. 2005. Dairy manure particle size distribution, properties, and implications for manure handling and treatment. ASAE Annual International Meeting, July 17-20, Tampa, Florida, USA.

Wu Z. 2007. Phosphorus and nitrogen distribution of screw press separated dairy manure with recovery of bedding material. Appl. Eng. Agric. 23:757-62.

Zhang R.H., Lei F. 1998. Chemical treatment of animal manure for solid-liquid separation. Trans. ASAE 41:1103-8.

Zhang R.H., Westerman P.W. 1997. Solid-liquid separation of animal manure for odor control and nutrient management. Appl. Eng. Agric. 23:757-62. 